\title{
Validation and Normative Data of the Spanish Version of the Face Name Associative Memory Exam (S-FNAME)
}

\author{
Vanessa Alviarez-Schulze ${ }^{1,2, *}$ @ $\left(\right.$, Gabriele Cattaneo ${ }^{1,2}$, Catherine Pachón-García ${ }^{1,2}$, Javier Solana-Sánchez $^{1,2}$, \\ Josep M. Tormos-Muñoz ${ }^{1,2}$, Montserrat Alegret ${ }^{3,4}$ (1) , Alvaro Pascual-Leone ${ }^{1,5,6}$, David Bartrés-Faz ${ }^{1,7}$, and the Barcelona Brain \\ Health Initiative group ${ }^{1,2}$ \\ ${ }^{1}$ Institut Guttmann, Institut Universitari de Neurorehabilitació adscrit a la UAB, Badalona 08916, Spain \\ ${ }^{2}$ Department of Medicine, Universitat Autònoma de Barcelona, Bellaterra 08035, Spain \\ ${ }^{3}$ Research Center and Memory Clinic, Fundació ACE, Institut Català de Neurociències Aplicades, Universitat Internacional de Catalunya, Barcelona 08029, \\ Spain \\ ${ }^{4}$ Networking Research Center on Neurodegenerative Diseases (CIBERNED), Instituto de Salud Carlos III, Madrid 28031, Spain \\ ${ }^{5}$ Hinda and Arthur Marcus Institute for Aging Research and Deanna and Sidney Wolk Center for Memory Health, Hebrew SeniorLife, Boston, MA 02131, USA \\ ${ }^{6}$ Department of Neurology, Harvard Medical School, Boston, MA 02115, USA \\ ${ }^{7}$ Departament de Medicina, Facultat de Medicina i Ciències de la Salut i Institut de Neurociències, Universitat de Barcelona, Barcelona 08036, Spain
}

(Received July 10, 2020; Final Revision December 24, 2020; Accepted January 5, 2021; First Published Online March 22, 2021)

\begin{abstract}
Objective: The relevance of the episodic memory in the prediction of brain aging is well known. The Face Name Associative Memory Exam (FNAME) is a valued associative memory measure related to Alzheimer's disease (AD) biomarkers, such as amyloid- $\beta$ deposition preclinical AD individuals. Previous validation of the Spanish version of the FNAME test (S-FNAME) provided normative data and psychometric characteristics. The study was limited to subjects attending a memory clinic and included a reduced sample with gender inequality distribution. The purpose of this study was to assess S-FNAME psychometric properties and provide normative data in a larger independent sample of cognitively healthy individuals. Method: S-FNAME was administered to 511 cognitively healthy volunteers (242 women, aged 41-65 years) participating in the Barcelona Brain Health Initiative cohort study. Results: Factor analysis supported construct validity revealing two underlying components: face-name and face-occupation and explaining 95.34\% of the total variance, with satisfactory goodness of fit. Correlations between S-FNAME and Rey AuditoryVerbal Learning Test were statistically significant and confirmed its convergent validity. We also found weak correlations with non-memory tests supporting divergent validity. Women showed better scores, and S-FNAME was positively correlated with education and negatively with age. Finally, we generated normative data. Conclusions: The S-FNAME test exhibits good psychometric properties, consistent with previous findings, resulting in a valid and reliable tool to assess episodic memory in cognitively healthy middle-aged adults. It is a promising test for the early detection of subtle memory dysfunction associated with abnormal brain aging.
\end{abstract}

Keywords: Episodic memory, memory and learning test, validation study, Alzheimer's disease, neuropsychologic test, cognitive aging.

\section{INTRODUCTION}

Episodic memory is part of the declarative memory system referred to as the ability to learn and store unique events or personal experiences (emotions, thoughts, and perceptions) that imply temporal and spatial data (Lezak, Howieson \& Loring, 2004; Pause et al., 2013; Weintraub et al., 2013).

*Correspondence and reprint requests to: Vanessa Alviarez-Schulze, Institut Guttmann, Institut Universitari de Neurorehabilitació adscrit a la UAB, Hospital de Neurorehabilitació, Camí de Can Ruti, s/n, 08916, Badalona 2347, Spain. E-mails: gcattaneo@guttmann.com; valviarez@ guttmann.com
This cognitive function decreases considerably in aging, with interindividual variability, prematurely reflecting critical neurocognitive disorders (Josefsson, De Luna, Pudas, Nilsson \& Nyberg, 2012; Henson et al., 2016). Sensitive indicators of abnormal aging changes in episodic memory measures have been associated with underlying preclinical AD pathological processes, such as grey matter atrophy in the hippocampus and entorhinal cortex, and brain amyloid$\beta$ and tau deposition (Weintraub et al., 2013; Tromp, Dufour, Lithfous, Pebayle \& Després, 2015; Duke-Han, Nguyen, Stricker \& Nation, 2017; Polcher et al., 2017; Lim et al., 2018). 
In this context, associative memory is an important domain in early AD diagnosis. Tasks involving cross-modal associations, as faces and names pairs due to its complex nature and high ecological validity, have been suggested as promising tools (Loewenstein, Curiel, Duara \& Buschke, 2018).

Neuroimaging studies have provided further support for using the face-name paradigm as a marker of prodromal AD (Rentz et al., 2013; Jurick et al., 2018). Findings revealed that the encoding and memory formation of novel associations is differentially impaired in AD's early stages compared with normal aging. This paradigm has also been used to optimize the characterization and differentiation of Mild Cognitive Impairment (MCI) subtypes (Rentz et al., 2011; Polcher et al., 2017; Jurick et al., 2018; Kormas et al., 2018; Rubiño \& Andrés, 2018).

Otherwise, valid, reliable, and sensitive tools are essential for explaining and predicting normal and pathological brain aging (Peña-Casanova et al., 2009; Amariglio et al., 2012; Papp et al., 2014; Nilsson \& Lövdén, 2018). At present, few tests are sensitive to preclinical changes in major neurocognitive disorders, even when examinees could normally perform on other traditional neuropsychological tests (Estévez-González, Kulisevsky, Boltes, Ortemín, \& García-Sánchez, 2003; Kielb, Weintraub, Rogalski, Weitner \& Rademaker, 2015; Rentz et al., 2013; Silva et al., 2013; Kormas et al., 2018).

Following the original Face Name Associative Memory Exam (FNAME; Rentz et al. 2011), a psychometrically equivalent short form (FNAME-12; Papp et al., 2014) and a computerized version (FACEmemory $囚$ ) have been created (Alegret et al., 2020). The FNAME, either the complete or short form, has been adapted and validated in several countries: Greek GR-FNAME12 version (Kormas et al., 2018), Spanish S-FNAME version (Alegret, Valero et al., 2015), and Latin American version named LAS-FNAME (VilaCastelar et al., 2019).

S-FNAME test consists of asking the examinees to remember 16 face-name pairs and 16 face-occupation pairs for a total of 32 cross-modal pairs. The initial learning phase includes initial cued recalls for face-name pairs and faceoccupation pairs followed by an immediate cued recall of both name and occupation associated with each face. Finally, a 30-Minute Delayed Cued Recall requires to evoke all information associated with each face after a 30-min delay (Alegret, Valero et al., 2015).

Previous validation studies confirmed construct validity using Factor Analysis (Alegret, Valero et al., 2015; Kormas et al., 2018) and discriminant validity comparing cognitively healthy, amnesic MCI, non-amnesic MCI individuals (Alegret et al., 2020).

Convergent validity has been previously tested calculating correlation with other memory tests as Rey Auditory-Verbal Learning Test, Rey-Osterrieth Complex Figure Test, Free, Cued Selective Reminding Test, and The Word List Learning test from the Wechsler Memory Scale-Third Edition (Amariglio et al., 2012; Papp et al., 2014; Alegret, Valero et al., 2015; Alegret et al., 2015; Vila-Castelar et al., 2019).
Similarly, divergent validity was tested by measuring correlation with non-memory tests (Papp et al., 2014; Alegret, Valero et al., 2015; Alegret et al., 2015; Vila-Castelar et al., 2019).

The FNAME Exam is currently considered a valuable tool within the clinical and research field. For example, according to Vila-Castelar et al. (2019), FNAME was applied in the US POINTER study (NCT03688126) whose objective was to reduce risks and protect the brain through lifestyle intervention. Also, the European Prevention of Alzheimer's Dementia (EPAD) Scientific Advisory Group for Clinical and Cognitive Outcomes recommended FNAME as an appropriate cognitive test associated with preclinical brain changes that should be included in clinical assessment protocols (Ritchie et al., 2017). In Catalonia, the S-FNAME is used in the Fundació ACE Healthy Brain Initiative (FACEHBI) (Rodriguez-Gomez et al., 2017), a broad longitudinal cohort of 200 middle-aged adults with Subjective Cognitive Decline, focused on increasing the understanding of preclinical AD.

As mentioned above, in Spain, Alegret et al. (2015) provided normative data and psychometric characteristics of SFNAME. However, this study revealed some limitations regarding the sample: although it was composed of cognitively healthy individuals, the sample was limited to subjects attending a memory clinic. The size was reduced $(n=110)$ with gender inequality distribution. In conclusion, given the relevance of assessing cross-modal associative face-name memory, as a sensitive measure of preclinical AD, we aimed to determine the validity and reliability of the S-FNAME test from a population-based larger sample, as well as to develop population-specific normative tables based on a Spanish sample between 41 and 65 years.

\section{METHODS}

\section{Participants}

This study was carried out within the in-person assessment of a longitudinal prospective population-based cohort study ongoing in Barcelona: the Barcelona Brain Health Initiative (BBHI; Cattaneo et al., 2018). 511 cognitively healthy volunteers (242 women) aged between 41 and 65 years $(M=52.66, S D=7.05)$ completed the neurocognitive assessment (Table 1) and were included in this study.

Most of the participants were Catalonia residents (96.09\%) and only $3.91 \%$ came from other areas within Spain. $95 \%$ of our participants were Catalan-Spanish bilinguals (5\% were only Spanish speakers). Catalan dominant bilinguals $(58.5 \%)$ reported to be early and high proficient bilinguals and regularly exposed to both languages, living most of them in a highly bilingual context, such as Barcelona city or its metropolitan area.

Participants with history or current neurological or psychiatric disease diagnosis, traumatic brain injury (TBI) with loss of consciousness, substance abuse/dependence, or treatment with psychopharmacological drugs were excluded. We excluded examinees with objective deficits in neuropsychological tests included in the BBHI protocol (see Cattaneo et al., 2018), 
Table 1. Frequencies of sociodemographic variables

\begin{tabular}{lcrrrrr}
\hline \hline \multirow{2}{*}{ Age Range } & & \multicolumn{2}{c}{$40-54$} & & \multicolumn{2}{c}{$55-65$} \\
\cline { 3 - 4 } \cline { 7 - 7 } & & $n$ & $\%$ & & $n$ & $\%$ \\
\hline Years of Education & $0-15$ & 66 & 22.5 & & 83 & 38.1 \\
& 16 & 227 & 77.5 & & 135 & 61.9 \\
& Total & 293 & 100.0 & 218 & 100.0 \\
Gender & Women & 142 & 48.5 & & 100 & 45.9 \\
& Men & 151 & 51.5 & & 118 & 54.1 \\
& Total & 293 & 100.0 & 218 & 100.0 \\
\hline \hline
\end{tabular}

and those who scored below 26 points on the Mini-Mental State Examination (Folstein, Folstein, \& McHugh, 1975; Blesa et al., 2001).

All participants provided explicit informed consent and the protocol was approved by the Comité d'Ètica $\mathrm{i}$ Investigació Clínica de la Unió Catalana d'Hospitals, local ethics committee.

\section{Procedures and Materials}

S-FNAME was administered according to the standardized procedure published by Alegret et al. (2015). The test was the first applied during BBHI cognitive assessment session (Cattaneo et al., 2018), and its administration took between 35 and $40 \mathrm{~min}$. It is essential to highlight that no other memory tests were applied between the S-FNAME initial learning and the 30-min delayed recall.

S-FAME application procedure began with the face study phase: subjects were presented all 16 faces, four faces to a page, each in a quadrant. Participants were requested to look at each face for $2 \mathrm{~s}$ while the professional pointed his/her finger on it. In the Initial study of face-name pairs (FN-N), participants were shown the same 16 faces with names underneath. They had to learn the name associated with each face during this single trial. Then, in the Initial cued recall of face-name pairs (ILN), the subjects were again presented faces and were asked to evoke each face's corresponding name. Scores were the result of correctly recalled pairs (ILN).

The Initial study of face-occupation pairs (FN-O) consisted of presenting the same 16 faces, but this time with occupations underneath. Subjects were requested to study occupation-face associations, and in the Initial cued recall of face-occupation pairs, examinees were shown the faces. They were asked to evoke the related occupation of each face. Scores were the result of correctly recalled pairs (ILO). Then in the Immediate cued recall, subjects were presented with all stimuli and asked to remember both names (CRN score) and occupations (CRO score) associated with each.

Finally, in the 30-min delayed cued recall, participants were again shown the faces and were asked to evoke the name (CRN30 score) and occupation (CRO30 score) associated with each face. All scores (ILN, ILO, CRN, CRO, CRN30, and CRO30) ranged from 0 to 16.

During the BBHI cognitive assessment session (Cattaneo et al., 2018), a comprehensive neuropsychological tests battery was administered in the following fixed order: S-FNAME Exam, direct and inverse digit span (PeñaCasanova et al., 2012), Trail Making Test part A and B (TMTA and TMTB, respectively) (Peña-Casanova et al., 2012), phonemic and semantic fluency tasks (PeñaCasanova et al., 2012), Reasoning Matrix subtest from Wechsler Adult Intelligence Scale- Fourth Edition (WAISIV) (Wechsler, 2012), Rey Auditory-Verbal Learning Test (RAVLT; Schmidt, 1996), Block Design subtest from WAIS-IV (Wechsler, 2012). Letter-Number Sequencing (Peña-Casanova et al., 2012), Coding and Cancellation subtests from WAIS-IV, and Corsi block-tapping test (PeñaCasanova et al., 2012). A 30-min delayed cued recall of the S-FNAME Exam was obtained before RAVLT. The cognitive assessment session was conducted by two expert neuropsychologists and lasted approximately $90 \mathrm{~min}$.

Neuropsychological tests used for validation purposes were: Rey Auditory-Verbal Learning Test (RAVLT; Schmidt, 1996), Trail Making Test parts A and B (TMTA and TMTB, respectively) (Peña-Casanova et al., 2012), Reasoning Matrix and Block Design subtests (Wechsler, 2012).

RAVLT was chosen to obtain convergent validity evidence considering it is one of the gold standard instruments for episodic memory assessment. We included First Trial, Total Learning, and Delayed Recall scores. The other non-mnesic tests were used to evaluate divergent validity, considering that these tasks measure different constructs (visuospatial and visuoconstructive abilities, fluid intelligence, processing speed, and cognitive flexibility) than those assessed by the FNAME.

\section{Data Analysis}

Statistical analyses were performed using SPSS version 22.0 (Statistical Package for Social Sciences, Chicago, IL, USA). The frequency table was presented (see Table 1) to illustrate the distribution of sociodemographic variables (age ranges, educational level, gender) (see Table 1). Descriptive analyses for age (continuous measure) and years of education were included (see Table 2).

Years of education were estimated by explicitly asking the participants to report the total time of formal education achieved counting from the time when education becomes obligatory in Spain (primary school). In Spain, the mandated educational system includes elementary/primary school (6 years), secondary obligatory school (4 years) and baccalaureate/high school or Middle Grade Vocational Training (2 years). Higher education comprises undergraduate degree (4 years) and postgraduate degrees (specialization, master, and $\mathrm{PhD}$ programs).

Also, S-FNAME scores: ILN, ILO, CRN, CRO, CRN30, CRO30, subtotal scores for names $(\mathrm{FN}-\mathrm{N}=\mathrm{ILN}+\mathrm{CRN}+$ CRN30) and occupations (FN-O $=\mathrm{ILO}+\mathrm{CRO}+\mathrm{CRO} 30)$ and total score (S-FNAME Total $=\mathrm{ILN}+\mathrm{ILO}+\mathrm{CRN}+$ $\mathrm{CRO}+\mathrm{CRN} 30+\mathrm{CRO} 30)$, as well as performance on the other neuropsychological tests were shown in Table 2. 
Table 2. Demographic variables, S-FNAME, and other cognitive tests scores

\begin{tabular}{lrrrr}
\hline \hline & Min & Max & Mean & SD \\
\hline Age & 41 & 65 & 52.66 & 7.05 \\
Education (years) & 8 & 29 & 17.27 & 3.70 \\
ILN & 0 & 16 & 6.68 & 3.68 \\
ILO & 0 & 16 & 9.35 & 3.26 \\
CRN & 0 & 16 & 5.03 & 3.64 \\
CRO & 0 & 16 & 8.76 & 3.35 \\
CRN30 & 0 & 16 & 5.00 & 3.68 \\
CRO30 & 0 & 16 & 8.57 & 3.42 \\
FN-N & 0 & 48 & 16.71 & 10.70 \\
FN-O & 0 & 48 & 26.68 & 9.81 \\
S-FNAME Total & 5 & 96 & 43.39 & 17.73 \\
I Trial RAVLT & 2 & 14 & 6.23 & 1.83 \\
RAVLT Total learning & 24 & 74 & 51.89 & 8.48 \\
RAVLT Delayed Recall & 4 & 15 & 11.31 & 2.60 \\
TMTA & 11 & 61 & 27.27 & 8.63 \\
TMTB & 34 & 276 & 79.61 & 28.44 \\
Matrix Reasoning WAIS-IV & 6 & 26 & 19.95 & 3.45 \\
Block Design WAIS-IV & 20 & 65 & 45.82 & 10.60 \\
\hline \hline
\end{tabular}

Note. ILN = initial learning for names score; ILO = initial learning for occupations score; $\mathrm{CRN}=$ immediate cued recall for names score; $\mathrm{CRO}=$ immediate cued recall for occupations; $\mathrm{CRN} 30=$ delayed cued recall for names; $\mathrm{CRO} 30=$ delayed cued recall for occupations; $\mathrm{FN}-\mathrm{N}=$ subtotal of face-name pairs; FN-O = subtotal of face-occupation pairs; S-FNAME Total = sum all SFNAME scores; I Trial RAVLT $=$ Trial I of Rey Auditory Verbal Learning Test; RAVLT Total Learning= Total recall between Trial I and Trial V of Rey Auditory-Verbal Learning Test; RAVLT Delayed Recall $=$ RAVLT recall after $30 \mathrm{~min}$; TMTA $=$ Trail Making Test part $\mathrm{A} ; \mathrm{TMTB}=$ Trail Making Test part B; B; Matrix Reasoning = subtest of Wechsler Adult Intelligence Scale IV; Block Design = subtest of Wechsler Adult Intelligence Scale IV.

To examine construct validity, we carried out an exploratory factor analysis (EFA) to determine the underlying factorial structure. Then, confirmatory factor analysis (CFA) was executed using IBM SPSS AMOS. To examine the goodness of fit of the factorial structures, we used the absolute, incremental, and indicators: Chi-square $\left(\chi^{2}\right)$, Normed Chi-square $\left(\chi^{2} / \mathrm{df}\right)$, Goodness of Fit Index (GFI), Adjusted Goodness Fit Index (AGFI), Root Mean Square Error of Approximation (RMSEA), Normed Fit Index (NFI), and Tucker-Lewis Index (TLI) (Hair, Anderson, Tatham, \& Black et al., 1999; Mulaik, 2009). Convergent validity was assessed using Pearson correlation coefficients between S-FNAME and RAVLT scores: RAVLT Total Learning (sum of RAVLT learning trials I, II, III, IV, and V) and RAVLT Delayed Recall (retrieval after $30 \mathrm{~min}$ ). Divergent validity was examined, measuring Pearson correlation coefficients with non-memory tests: TMTA, TMTB, and Matrix Reasoning and Block Design subtests from WAIS-IV. Reliability was calculated using Cronbach's $\alpha$ to assess the internal consistency of S-FNAME.

Correlation indices between demographic variables and S-FNAME scores were calculated, and to confirm the contribution of gender, age, and education on S-FNAME scores were used s. multiple linear regression analyses.
Finally, an Analysis of Variance (ANOVA) was used to examine the multivariate effect of gender, age ranges $(<55$ and $\geq 55$ years old), and educational level $(<16$ and $\geq 16$ years of formal education) for all the S-FNAME scores (ILN, ILO, CRN, CRO, CRN30, CRO30, subtotals FN-N, FN-O, and S-FNAME Total). The configuration of the age groups was obtained after multiple comparisons between different age ranges, in order to guarantee that the resulting groups reflected significant differences in S-FNAME scores, instead of arbitrarily dividing age (Ferreira \& Campagna, 2014).

Then, norms were generated considering the combination of those variables that reflected a significant effect. For all the analyses, statistical significance was determined when $p<.05$.

\section{RESULTS}

Gender, age ranges (41-54 and 55-65 years), and educational level ( $<16$ and $\geq 16$ years) are represented in Table 1 ; these categorical variables were used to develop normative tables. We found a homogeneous gender distribution $(p=.25)$. Gender resulted not different between age ranges $\left(\chi^{2}(1)=\right.$ $.337 ; p=.56)$. Also, educational level was similar for gender distribution $\left(\chi^{2}(1)=.490 ; p=.48\right)$.

Descriptive analyses for age, years of formal education, S-FNAME performance (ILN, ILO, CRN, CRO, CRN30, CRO30, FN-N, FN-O, and S-FNAME Total), and other neurocognitive tests scores used for validation are represented in Table 2. As shown, subjects obtained higher scores on the occupation-face than on the total face-name tests.

\section{Validation}

Pairwise correlation coefficients revealed $\mathrm{FN}-\mathrm{N}$ was positively associated with FN-O $(r=.49, p<.001)$ and subtotals (FN-N and FN-O) showed a statistically significant positive correlation with S-FNAME Total score $(r=.88$ and $r=.85$; $p<.001$ ) (Table 3 ). In addition, S-FNAME showed excellent internal consistency $(\alpha=.918)$.

S-FNAME scores and age were negatively correlated $(p<.001)$. Instead, the association between years of formal education and S-FNAME scores reflected a positive trend $(p<.001)$ (Table 3).

To examine the construct validity of S-FNAME, we ran an exploratory factor analysis (AFE) followed by confirmatory factor analysis. AFE was carried out using principal component analysis and direct Oblimin rotation (Hair et al., 1999). The factor analysis was viable according to the KaiserMeyer-Olkin measure of sampling adequacy (KMO = $.821)$, and Bartlett's test of sphericity $\left(\chi^{2}(15)=4638.35\right.$; $p<.001)$. The determinant of the correlation matrix was, as expected, near to 0 (0.001; Hair et al., 1999).

EFA yielded two factors with an eigenvalue greater than 1 . This solution explained $95.34 \%$ of the total variance of the construct. The two-factor model showed that factor 1 loads name scores (ILN, CRN, CRN30) and factor 2 were related to occupation scores (ILO, CRO, CRO30), as expected based 
Table 3. Pairwise correlation coefficients

\begin{tabular}{lcrr}
\hline \hline & FN-N & FN-O & FN-Total \\
\hline Age & $-.25^{* *}$ & $-.26^{* *}$ & $-.30^{* *}$ \\
Education (years) & $.17^{* *}$ & $.20^{* *}$ & $.21^{* *}$ \\
FN-N & & $.49^{* *}$ & $.88^{* *}$ \\
FN-O & & & $.85^{* *}$ \\
\hline \hline
\end{tabular}

$* * p<.001$.

Table 4. S-FNAME factor structure obtained from EFA

\begin{tabular}{|c|c|c|}
\hline \multicolumn{3}{|c|}{ Matrix of structure } \\
\hline & \multicolumn{2}{|c|}{ Component } \\
\hline & 1 & 2 \\
\hline $\mathrm{CRO}$ & .99 & .48 \\
\hline CRO30 & .99 & .48 \\
\hline ILO & .97 & .48 \\
\hline CRN30 & .47 & .98 \\
\hline $\mathrm{CRN}$ & .47 & .98 \\
\hline ILN & .50 & .96 \\
\hline
\end{tabular}

on theory and previous findings (Table 4). Following the confirmatory modeling strategy (Hair et al., 1999), we carried out a confirmatory factor analysis for the two-factor model to verify its goodness of fit.

AFC revealed satisfactory goodness of fit values. Chi squares value $\left(\chi^{2}(8)=21.86 ; p=.005\right)$ is low, but it is statistically significant. A $p$-value greater than .05 is expected, but it is important to note that this indicator should not be considered determining in large populations due to its lack of sensitivity. Thus, $\chi^{2} / \mathrm{df}$ index is more appropriate due to its lower sensitivity to sample size; $\chi^{2} / \mathrm{df}=2.73$ showed adequate absolute goodness of fit (Hair et al., 1999; Mulaik, 2009). GFI and AGFI were satisfactory, above .95 (GFI = .98; AGFI = .96). Also, RMSEA was within an acceptable range, between .05 and .08 (RMSEA $=.058)$. Regarding the incremental fit indicators, NFI and TLI were above .90 , reflecting good fit $(\mathrm{NFI}=$.97; TLI = .96) (Hair et al., 1999; Mulaik, 2009).

To examine the convergent validity of S-FNAME Pearson correlation coefficients $(r)$ were calculated between S-FNAME (ILN, ILO, FN-N, FN-o, and S-FNAME Total) and RAVLT scores (Trial I, Total Learning and Delayed Recall). Statistically significant $(p<.001)$ associations were found for both RAVLT scores with medium effect size (Table 5).

According to divergent validity, we obtained Pearson correlation coefficients between S-FNAME scores and nonmemory test. We found an inverse association between S-FNAME scores and TMTA and TMTB scores $(p<.001)$, except the correlation between FN-O and TMTA, which is close to 0 . Also, a positive association $(p<.001)$ resulted between S-FNAME measures and Matrix Reasoning, Block Design of WAIS-IV, but with a small effect size (Table 5).
To confirm evidence of discriminant validity, we used Steiger's $Z$ (1980) statistic to compare correlations between S-FNAME Total and non-memory test scores with those obtained by measuring convergent validity. Correlation between S-FNAME Total and Matrix Reasoning scores was, at a statistically significant level, lower than the correlation between S-FNAME Total and both RAVLT variables scores (Steiger's $Z=-5.55, \mathrm{p}<.001$; Steiger's $Z=-5.26$; Steiger's $Z=-2.55$; Steiger's $Z=-3.32, p<.001)$. Likewise, correlation coefficient between S-FNAME Total and Block Design performances was significantly lower than the correlation index between S-FNAME Total and both RAVLT variables scores (Steiger's $Z=-5.99, p<.001$; Steiger's $Z=-5.57$; Steiger's $Z=-2.37$; Steiger's $Z=-2.51, p<.001)$.

\section{Normative Data}

Multiple regression linear analyses were carried out to examine the demographic variables' contribution as predictors of S-FNAME performance. The results confirmed the significant contribution of age, gender, and year of formal education to the variance of S-FNAME scores $(p<.001)$, as illustrated in Table 6.

Therefore, prior to the development of normative tables, we determined the effect of age ranges ( $<55$ and $\geq 55$ years), gender and educational level ( $<16$ and $\geq 16$ years) on S-FNAME performance using ANOVA. Previously, homoscedasticity was confirmed using Levene test of equality of variance. Gender $\left(F(1,503)=33.05, p<.001, \eta^{2}=.06\right)$, age $\left(F(1,503)=14.82, p<.001, \eta^{2}=.03\right)$, and educational level $\left(F(1,503)=9.95, p=.002, \eta^{2}=.02\right)$ showed a statistically significant effect on FN-N score. Regarding to FN-O performance, age $(F(1,503)=15.85, p<.001$, $\left.\eta^{2}=.03\right)$, educational level $(F(1,503)=13.35, p<.001$, $\left.\eta^{2}=.03\right)$, and gender $(F(1,503)=12.19, p=.001$, $\left.\eta^{2}=.02\right)$, reflected statistically significant influence. Likewise, gender $\left(F(1,503)=30.21, p<.001, \eta^{2}=.06\right)$, age $\left(F(1,503)=21.28, p<.001, \eta^{2}=.04\right)$, an education $\left(F(1,503)=16.02, p<.001, \eta^{2}=0.03\right)$, groups differed significantly in terms of their performance on S-FNAME Total. Interaction effects between demographics variables were no observed for any of the S-FNAME measures. Findings showed older than 55 years, less than 16 years of education and men obtained the lowest S-FNAME scores.

Finally, we stratified scores by gender, age, and educational level in Table 7 and calculated norms through percentile transformations (see Tables 8-10).

\section{DISCUSSION}

The present study aimed to assess the psychometric properties of the S-FNAME and develop normative data based on a large sample of cognitively healthy middle-aged adults. The refinement of highly sensitive measures to detect major neurocognitive disorders' prodromal markers is extremely valuable and needed work (Polcher et al., 2017). 
Table 5. Correlation coefficients between S-FNAME, RAVLT, and non-memory tests scores

\begin{tabular}{lccccccc}
\hline \hline & I TRIAL RAVTL & RAVLT Total Learning & RAVLT Delayed Recall & TMTA & TMTB & Matrix Reasoning & Block Design \\
\hline ILN & $.27^{* *}$ & $.40^{* *}$ & $.38^{* *}$ & -.14 & -.17 & $.14^{* *}$ \\
ILO & $.31^{* *}$ & $.40^{* *}$ & $.37^{* *}$ & -.08 & $-.13^{* *}$ & $.17^{* *}$ & $.13^{* *}$ \\
FN-N & $.26^{* *}$ & $.39^{* *}$ & $.39^{* *}$ & $-.14^{* *}$ & $-.16^{* *}$ & $.15^{* *}$ & $.16^{* *}$ \\
FN-O & $.30^{* *}$ & $.41^{* *}$ & $.39^{* *}$ & -.08 & $-.13^{* *}$ & $.17^{* *}$ & $.12^{* *}$ \\
S-FNAME & $.32^{* *}$ & $.46^{* *}$ & $.45^{* *}$ & $-.13^{* *}$ & $-.17^{* *}$ & $.19^{* *}$ \\
Total & & & & & & \\
\hline
\end{tabular}

$* * p<.01$.

Table 6. Contribution of age, gender, and education on S-FNAME scores

\begin{tabular}{llccc}
\hline \hline Measure & Predictor & Standardized $\beta$ & $t$ & $p$ value \\
\hline \multirow{2}{*}{ FN-N } & Age & -.23 & -5.58 & $<R^{2}$ \\
& Gender & -.28 & -6.82 & $<.001$ \\
FN-O & Education (years) & .16 & 3.77 & $<.001$ \\
& Age & -.24 & -5.66 & $<.001$ \\
& Gender & -.17 & -4.05 & $<.001$ \\
S-FNAME total & Education (years) & .18 & 4.17 & $<.001$ \\
& Age & -.27 & -6.67 & $<.001$ \\
& Gender & -.26 & -6.51 & $<.001$ \\
& Education (years) & .19 & 4.71 & $<.001$ \\
\hline \hline
\end{tabular}

Table 7. Performances on S-FNAME according to gender, age range, and educational level

\begin{tabular}{|c|c|c|c|c|c|c|c|c|}
\hline \multirow{4}{*}{$\begin{array}{l}\text { S-FNAME } \\
\text { scores }\end{array}$} & \multicolumn{4}{|c|}{ Women } & \multicolumn{4}{|c|}{ Men } \\
\hline & \multicolumn{2}{|c|}{ Age $40-54$} & \multicolumn{2}{|c|}{ Age 55-65 } & \multicolumn{2}{|c|}{ Age $40-54$} & \multicolumn{2}{|c|}{ Age 55-65 } \\
\hline & $\begin{array}{c}<16 \\
\text { Education } \\
\text { (years) }\end{array}$ & $\begin{array}{c}\geq 16 \\
\text { Education } \\
\text { (years) }\end{array}$ & $\begin{array}{c}<16 \\
\text { Education } \\
\text { (years) }\end{array}$ & $\begin{array}{c}\geq 16 \\
\text { Education } \\
\text { (years) }\end{array}$ & $\begin{array}{c}<16 \\
\text { Education } \\
\text { (years) }\end{array}$ & $\begin{array}{c}\geq 16 \\
\text { Education } \\
\text { (years) }\end{array}$ & $\begin{array}{c}<16 \\
\text { Education } \\
\text { (years) }\end{array}$ & $\begin{array}{c}\geq 16 \\
\text { Education } \\
\text { (years) }\end{array}$ \\
\hline & $M(S D)$ & $M(S D)$ & $M(S D)$ & $M(S D)$ & $M(S D)$ & $M(S D)$ & $M(S D)$ & $M(S D)$ \\
\hline ILN & $7.28(3.59)$ & $8.62(3.74)$ & $6.48(3.17)$ & $7.12(3.47)$ & $6(3.2)$ & $6.42(3.57)$ & $3.98(2.4)$ & $5.56(3.56)$ \\
\hline ILO & $9.41(2.66)$ & $10.7(3.11)$ & 8.57 (3.05) & $9.72(2.8)$ & $8.71(3.12)$ & $9.81(3.48)$ & 7.61 (2.77) & $8.05(3.13)$ \\
\hline CRN & $5.47(3.03)$ & $6.87(3.83)$ & $4.90(3.30)$ & $5.48(3.56)$ & $4.06(3.23)$ & $5.09(3.59)$ & $2.34(2.03)$ & 3.69 (3.35) \\
\hline CRO & $8.69(2.81)$ & $10.12(3.19)$ & $7.81(2.87)$ & $9.22(2.97)$ & $7.85(3.42)$ & $9.49(3.41)$ & $6.90(3.09)$ & $7.31(3.17)$ \\
\hline CRN30 & $5.47(3.15)$ & 7 (3.89) & $4.86(3.17)$ & $5.47(3.79)$ & $4.12(3.21)$ & $4.85(3.58)$ & $2.39(2.08)$ & $3.70(3.29)$ \\
\hline CRO30 & $8.75(2.68)$ & $9.82(3.26)$ & $7.5(2.98)$ & $9.17(3.02)$ & $7.76(3.54)$ & $9.28(3.62)$ & $6.73(3.15)$ & 7.08 (3.06) \\
\hline FN-N & $18.21(9.48)$ & $22.49(11.20)$ & $16.24(9.32)$ & $18.07(10.45)$ & $14.18(9.33)$ & $16.36(10.45)$ & $8.71(6.19)$ & $12.95(9.79)$ \\
\hline $\mathrm{FN}-\mathrm{O}$ & $26.84(7.84)$ & $30.63(9.33)$ & $23.88(8.61)$ & $28.12(8.59)$ & $24.32(9.87)$ & $28.58(10.37)$ & $21.24(8.69)$ & $22.44(9.17)$ \\
\hline $\begin{array}{l}\text { S-FNAME } \\
\text { Total }\end{array}$ & $45.06(14.32)$ & $53.12(17.84)$ & $40.11(15.27)$ & $46.19(15.63)$ & $38.5(16.11)$ & $44.94(17.47)$ & 29.95 (11.79) & $35.39(16.8)$ \\
\hline
\end{tabular}

Face-Name Association tests are highly demanding and cross-modal measures that, due to their complexity, minimize possible compensating strategies and are capable of identifying changes not detected by other tests (Loewenstein et al., 2018; Rubiño \& Andrés, 2018; Alegret et al., 2020).

Our results confirmed that S-FNAME is a valid and reliable measure. Factor analysis revealed two underlying dimensions with satisfactory goodness of fit. Face-occupation association pairs (ILO, CRO, CRO30) loaded to a first component while face-name association pairs (ILN, CRN, CRN30) to the second one. This two-factor model demonstrates the test's construct validity and supports previous FNAME validation findings (Amariglio et al., 2012; Alegret et al., 2015; Kormas et al., 2018).

Convergent validity was demonstrated with strong and positive correlations with RAVLT, a traditional and widely used episodic-memory test. Specifically, initial learning and long-term memory RAVLT scores showed statistically 
Table 8. Normative data for FN-N scores

\begin{tabular}{|c|c|c|c|c|c|c|c|c|}
\hline \multirow[b]{3}{*}{ Percentile } & \multicolumn{4}{|c|}{ Women } & \multicolumn{4}{|c|}{ Men } \\
\hline & \multicolumn{2}{|c|}{$41-54$ years } & \multicolumn{2}{|c|}{$55-65$ years } & \multicolumn{2}{|c|}{$41-54$ years } & \multicolumn{2}{|c|}{$55-65$ years } \\
\hline & $\begin{array}{c}<16 \text { Years of } \\
\text { Education }\end{array}$ & $\begin{array}{l}>16 \text { Years of } \\
\text { Education }\end{array}$ & $\begin{array}{c}<16 \text { Years of } \\
\text { Education }\end{array}$ & $\begin{array}{c}>16 \text { Years of } \\
\text { Education }\end{array}$ & $\begin{array}{c}<16 \text { Years of } \\
\text { Education }\end{array}$ & $\begin{array}{l}>16 \text { Years of } \\
\text { Education }\end{array}$ & $\begin{array}{c}<16 \text { Years of } \\
\text { Education }\end{array}$ & $\begin{array}{l}>16 \text { Years of } \\
\text { Education }\end{array}$ \\
\hline 2 & 0 & $\leq 4$ & $\leq 2$ & $\leq 3$ & $\leq 1$ & $\leq 2$ & $\leq 1$ & 0 \\
\hline 5 & $1-3$ & $5-7$ & $3-4$ & $4-5$ & 2 & 3 & 2 & 1 \\
\hline 10 & 4 & $8-9$ & $5-6$ & $6-7$ & $3-4$ & $4-5$ & - & $2-3$ \\
\hline 15 & $5-7$ & 10 & - & 8 & 5 & 6 & 3 & $4-5$ \\
\hline 20 & $8-10$ & $11-12$ & 7 & 9 & 6 & 7 & - & - \\
\hline 25 & $11-13$ & 13 & 8 & 10 & - & 8 & 4 & 6 \\
\hline 30 & 14 & $14-15$ & $9-10$ & - & 7 & 9 & 5 & 7 \\
\hline 35 & - & 16 & 11 & 11 & $8-9$ & $10-11$ & - & 8 \\
\hline 40 & $15-16$ & $17-18$ & 12 & 12 & 10 & 12 & 6 & 9 \\
\hline 45 & $17-18$ & 19-21 & 13 & $13-14$ & 11 & 13 & 7 & $10-11$ \\
\hline 50 & 19 & $22-23$ & $14-15$ & $15-16$ & 12 & 14 & 8 & 12 \\
\hline 55 & 20 & 24 & $16-17$ & 17 & $13-14$ & $15-16$ & - & 13 \\
\hline 60 & $21-22$ & $25-26$ & $18-19$ & $18-19$ & $15-16$ & 17 & 9 & 14 \\
\hline 65 & 23 & $27-28$ & 20 & $20-22$ & $17-18$ & $18-19$ & 10 & 15 \\
\hline 70 & 24 & $29-30$ & 21 & $23-25$ & $19-20$ & $20-21$ & 11 & 16 \\
\hline 75 & 25 & $31-32$ & 22 & 26 & $21-23$ & $22-23$ & $12-13$ & $17-18$ \\
\hline 80 & 26 & $33-34$ & $23-24$ & $27-29$ & 24 & $24-29$ & 14 & 19-20 \\
\hline 85 & 27 & $35-37$ & $25-28$ & 30 & $25-26$ & 30 & $15-16$ & $21-23$ \\
\hline 90 & $28-32$ & $38-39$ & 29-33 & $32-37$ & $27-31$ & $31-34$ & $17-20$ & $24-30$ \\
\hline 95 & $33-38$ & $40-43$ & 34-39 & $38-43$ & $32-35$ & $35-40$ & $21-26$ & $31-40$ \\
\hline 98 & $\geq 39$ & $\geq 44$ & $\geq 40$ & $\geq 44$ & $\geq 36$ & $\geq 41$ & $\geq 27$ & $\geq 41$ \\
\hline
\end{tabular}

Table 9. Normative data for FN-O scores

\begin{tabular}{|c|c|c|c|c|c|c|c|c|}
\hline \multirow[b]{3}{*}{ Percentile } & \multicolumn{4}{|c|}{ Women } & \multicolumn{4}{|c|}{ Men } \\
\hline & \multicolumn{2}{|c|}{$41-54$ years } & \multicolumn{2}{|c|}{$55-65$ years } & \multicolumn{2}{|c|}{$41-54$ years } & \multicolumn{2}{|c|}{$55-65$ years } \\
\hline & $\begin{array}{c}<16 \text { Years of } \\
\text { Education }\end{array}$ & $\begin{array}{l}>16 \text { Years of } \\
\text { Education }\end{array}$ & $\begin{array}{c}<16 \text { Years of } \\
\text { Education }\end{array}$ & $\begin{array}{l}>16 \text { Years of } \\
\text { Education }\end{array}$ & $\begin{array}{c}<16 \text { Years of } \\
\text { Education }\end{array}$ & $\begin{array}{l}>16 \text { Years of } \\
\text { Education }\end{array}$ & $\begin{array}{l}<16 \text { Years of } \\
\text { Education }\end{array}$ & $\begin{array}{c}>16 \text { Years of } \\
\text { Education }\end{array}$ \\
\hline 2 & $\leq 12$ & $\leq 10$ & $\leq 10$ & $\leq 13$ & $\leq 12$ & $\leq 11$ & $\leq 6$ & $\leq 8$ \\
\hline 5 & 13 & $11-15$ & 12 & $14-16$ & 13 & $12-16$ & $7-8$ & $9-11$ \\
\hline 10 & $14-17$ & $16-18$ & $13-14$ & 17 & $14-18$ & $17-18$ & $9-10$ & $12-13$ \\
\hline 15 & $18-19$ & $19-21$ & 15 & 18 & 19 & $19-21$ & $11-12$ & 14 \\
\hline 20 & 20 & $22-24$ & 16 & $19-20$ & $20-21$ & $22-24$ & 13 & 15 \\
\hline 25 & 21 & $25-26$ & $17-18$ & $21-23$ & 22 & $25-26$ & 14 & 16 \\
\hline 30 & 22 & 27 a 28 & 19 & 24 & 23 & $27-28$ & 15 & 17 \\
\hline 35 & 23 & 29 & 20 & 25 & 24 & 29 & $16-18$ & 18 \\
\hline 40 & 24 & 30 & - & 26 & - & 30 & $19-20$ & 19 \\
\hline 45 & 25 & 31 & 21 & 27 & 25 & 31 & 21 & 20 \\
\hline 50 & 26 & 32 & 22 & 28 & 26 & 32 & 22 & $21-22$ \\
\hline 55 & $27-28$ & 33 & 23 & 29 & $27-28$ & 33 & 23 & 23 \\
\hline 60 & $29-30$ & 34 & 24 & 30 & $29-30$ & 34 & 24 & 24 \\
\hline 65 & $31-33$ & 35 & $25-26$ & $31-32$ & $31-33$ & 35 & $25-26$ & $25-26$ \\
\hline 70 & - & 36 & $27-30$ & 33 & 34 & 36 & - & 27 \\
\hline 75 & 34 & 37 & $31-32$ & $34-35$ & - & 37 & 27 & $28-29$ \\
\hline 80 & 35 & $38-39$ & 33 & $36-37$ & 35 & $38-39$ & $28-29$ & $30-33$ \\
\hline 85 & 36 & $40-41$ & $34-35$ & 38 & 36 & $40-41$ & 30 & $34-35$ \\
\hline 90 & $37-38$ & $42-43$ & $36-39$ & $39-42$ & $37-38$ & $42-44$ & $31-35$ & $36-38$ \\
\hline 95 & 39 & $44-45$ & $40-44$ & $43-44$ & 39 & 45 & $36-41$ & 39 \\
\hline 98 & $\geq 40$ & $\geq 46$ & $\geq 45$ & $\geq 45$ & $\geq 40$ & $\geq 46$ & $\geq 42$ & $\geq 40$ \\
\hline
\end{tabular}


Table 10. Normative data for S-FNAME total scores

\begin{tabular}{|c|c|c|c|c|c|c|c|c|}
\hline \multirow[b]{3}{*}{ Percentile } & \multicolumn{4}{|c|}{ Women } & \multicolumn{4}{|c|}{ Men } \\
\hline & \multicolumn{2}{|c|}{$41-54$ years } & \multicolumn{2}{|c|}{ 55-65 years } & \multicolumn{2}{|c|}{$41-54$ years } & \multicolumn{2}{|c|}{$55-65$ years } \\
\hline & $\begin{array}{l}<16 \text { Years of } \\
\text { Education }\end{array}$ & $\begin{array}{l}>16 \text { Years of } \\
\text { Education }\end{array}$ & $\begin{array}{l}<16 \text { Years of } \\
\text { Education }\end{array}$ & $\begin{array}{l}>16 \text { Years of } \\
\text { Education }\end{array}$ & $\begin{array}{c}<16 \text { Years of } \\
\text { Education }\end{array}$ & $\begin{array}{l}>16 \text { Years of } \\
\text { Education }\end{array}$ & $\begin{array}{l}<16 \text { Years of } \\
\text { Education }\end{array}$ & $\begin{array}{c}>16 \text { Years of } \\
\text { Education }\end{array}$ \\
\hline 2 & $\leq 16$ & $\leq 17$ & $\leq 17$ & $\leq 25$ & $\leq 9$ & $\leq 18$ & $\leq 11$ & $\leq 10$ \\
\hline 5 & $17-25$ & $18-25$ & 18 & 26 & $10-16$ & 19 a 22 & $12-15$ & $11-14$ \\
\hline 10 & $26-29$ & $26-34$ & $19-22$ & $27-28$ & $17-19$ & 23 & 16 & $15-17$ \\
\hline 15 & 30 & $35-39$ & $23-26$ & 29 & $20-24$ & $24-26$ & $17-18$ & $18-21$ \\
\hline 20 & $31-32$ & $40-41$ & $27-28$ & $30-31$ & $25-28$ & $27-29$ & $19-20$ & 22 \\
\hline 25 & $33-35$ & $42-43$ & 29 & $32-36$ & 29 & $30-32$ & $21-22$ & $23-24$ \\
\hline 30 & $36-38$ & 44 & 30 & $37-38$ & 30 & $33-37$ & $22-24$ & $25-26$ \\
\hline 35 & $39-40$ & $45-46$ & $31-33$ & $39-40$ & $31-32$ & $38-39$ & - & $27-29$ \\
\hline 40 & $41-43$ & $47-49$ & $34-36$ & 41 & $33-34$ & $40-42$ & 25 & $30-32$ \\
\hline 45 & $44-45$ & $50-51$ & $37-38$ & 42 & $35-36$ & $43-44$ & $26-28$ & $33-34$ \\
\hline 50 & $46-48$ & $52-55$ & $39-41$ & 43 & 37 & $45-46$ & $29-30$ & 35 \\
\hline 55 & $49-50$ & $56-58$ & $42-43$ & $44-46$ & $38-41$ & $47-49$ & $31-32$ & $36-37$ \\
\hline 60 & 51 & $59-60$ & $44-45$ & $47-48$ & $42-43$ & $50-51$ & 33 & 38 \\
\hline 65 & $52-53$ & $61-63$ & 46 & $49-53$ & $44-45$ & $52-54$ & 34 & 39 \\
\hline 70 & $54-56$ & 64-66 & $47-48$ & $54-57$ & $46-48$ & 55 & $35-37$ & $40-42$ \\
\hline 75 & $57-58$ & 67 & $49-50$ & $58-61$ & $49-52$ & $56-59$ & $38-40$ & $43-46$ \\
\hline 80 & 59 & $68-71$ & $51-55$ & 62 & $53-56$ & $60-63$ & 41 & $47-50$ \\
\hline 85 & 60 & $72-76$ & $56-64$ & $63-68$ & $57-61$ & $64-67$ & $42-45$ & $51-53$ \\
\hline 90 & $61-63$ & $77-80$ & $65-69$ & 69-73 & $62-67$ & $68-71$ & $46-50$ & $54-70$ \\
\hline 95 & 64-73 & $81-85$ & $70-73$ & $74-80$ & $68-71$ & $72-78$ & $51-56$ & $71-77$ \\
\hline 98 & $\geq 74$ & $\geq 86$ & $\geq 74$ & $\geq 81$ & $\geq 72$ & $\geq 79$ & $\geq 57$ & $\geq 78$ \\
\hline
\end{tabular}

significant association with immediate and delayed recall face-name and face-occupation scores, respectively. These results confirmed, like previous studies, that S-FNAME is an episodic memory test (Amariglio et al., 2012; Papp et al., 2014; Alegret, Valero, et al., 2015; Alegret et al., 2015; Kormas et al., 2018; Vila-Castelar et al., 2019).

Furthermore, we found inverse correlations between S-FNAME and TMT performance and positive, but with small effect size, correlation with Matrix Reasoning and Block Design. All of these standardized tests are non-memory measures. Negative associations with tests measuring cognitive functions other than memory, lower than relations with memory tests, give evidence to divergent validity of S-FNAME. Findings are similar to those reported in previous research (Alegret, Valero et al., 2015; Alegret et al., 2015; Kormas et al., 2018; Vila-Castelar et al., 2019). Results also revealed excellent internal consistency of the test, supporting its reliability.

S-FNAME performance was related to gender, age, and educational level. Women obtained higher scores than men on all S-FNAME scores, as previously reported by Alegret, Valero et al. (2015). Previous findings have described that women's performance on episodic memory tasks is higher (Andreano \& Cahill, 2009). Also, our findings are in line with the results of Rentz et al. (2017), which demonstrated that women scored higher than men in early midlife. Still, gender differences were attenuated after menopause, especially in coding and evocation, with differences in storage and consolidation remaining.
Regarding age, most of the validation studies reported negative association FNAME scores (Amariglio et al., 2012; Alegret, Valero, et al., 2015; Kormas et al., 2018; Vila-Castelar et al., 2019; Alegret et al., 2020), as is expected considering the well-known memory decline in aging (Lezak et al., 2004; Peña-Casanova et al., 2009; Josefsson et al., 2012; Henson et al., 2016).

Concerning education, there are previous contradictory results; while some studies reported a significant positive effect similar to our findings (Papp et al., 2014; VilaCastelar et al., 2019), other authors failed to find this association (Amariglio et al., 2012; Alegret, Valero et al., 2015; Kormas et al., 2018). This apparent inconsistency is possibly due to methodological issues and cultural differences in the samples used. In this line, Rubiño \& Andrés (2018) highlight that the effect of age and educational level should be experimentally examined and must be verified in future studies using appropriate versions of the test in different samples.

Face-name component scores outperformed face-occupation component scores. It has been suggested that the face-name task is more sensitive to detect early changes in abnormal aging due to it is a more demanding and ecologically relevant task in older adults. It has also been related to higher brain $\mathrm{A} \beta$ deposition in healthy individuals with subjective cognitive decline (Rentz et al., 2011; Jurick et al., 2018). Specifically, using S-FNAME, the worse face-name performance was significantly related to higher amyloid- $\beta$ deposition in the bilateral Posterior Cingulate Cortex (Sanabria et al., 2018). Rentz et al. (2017) and 
Rubiño \& Andrés (2018) explained that face-name associations imply pairing unrelated, abstract, and unique information making it more difficult than face-occupation associations that involve previously stored semantic knowledge.

Finally, we developed valuable normative data. Carrying out standardization studies is exceptionally relevant in clinical neuropsychology and research fields (Lezak et al., 2004; Peña-Casanova et al., 2009; Alegret et al., 2012; Del Pino, Peña, Schretlen, Ibarretxe-Bilbao\& Ojeda, 2015).

S-FNAME is a promising tool for detecting a subtle decline in abnormal aging (Ritchie et al., 2017; Loewenstein et al., 2018). Population-specific normative tables for the age range included in this study are handy considering the importance of early detection of meaningful preclinical $\mathrm{AD}$ changes. Standardize and validate sensitive tests allow a better understanding of prodromal dementia and the application of timely treatment to prevent disability (Ritchie et al., 2017; Buckley \& Pascual-Leone, 2020).

\section{Limitations}

Our sample size was satisfactory for psychometric studies (Prieto \& Muñiz, 2000; Evers, Sijtsma, Lucassen, \& Meijer, 2010) and met the requirements to run factorial analyses (Hair et al., 1999; Costello \& Osborne, 2005). Also, it was larger than those used in previous validation studies in Spain, which mentioned sample size and gender distribution as a limitation (Alegret, Valero et al., 2015). However, for normative studies, larger samples are recommended to obtain subgroups with a sufficient number of subjects according to the distribution of sociodemographic variables.

Also, our sample was representative of the current Spanish population in terms of age and gender. However, it does not offer a representative sample of the educational distribution (Instituto Nacional de Estadística [INE], 2019). Our cohort includes a large proportion of participants with a superior educational level and a reduced number of individuals with elementary or secondary obligatory school completed. Therefore, the main limitation of our study is that the level of education of the sample is above the Spanish population average.

Del Pino et al. (2015) noted that an unequal distribution and overrepresentation of highly educated individuals are recurrent in Spanish normative studies. Psychometric studies of other memory tests have also faced such limitations (Speer et al., 2013; Lavoie et al., 2018). Specifically, in previous validation studies of the FNAME Exam, Alegret et al. (2012) and Papp et al. (2014) divided educational level using the same cut-off point (16 years of formal education).

Further, a recent study examining the relationship between educational measures and dementia risk suggests that the stratification in high and low education (i.e., tertiary $v s$. non-tertiary education) revealed the strongest associations (Then et al., 2016).

It is crucial to emphasize that clinicians must be careful when interpreting the results derived from these norms during the evaluation of individuals with low educational levels. As
Alegret et al. (2012) mentioned, ideally, normative research would obtain data from epidemiological sampling; however, when individuals are recruited into studies through referral clinics, it is common to find bias regarding the educational level or socioeconomic status. Hence, we strongly recommend to stratify the sample of future research according to specific educational levels of the Spanish system.

The sample was obtained from the baseline assessment of the BBHI cohort study and, consequently, it is composed of healthy, cognitively unimpaired subjects. A limitation of our psychometric study is the lack of clinical samples that would allow us to determine the sensitivity and specificity of the SFNAME. Such data are important within the aging assessment practice to choose instruments capable of detecting cognitive impairment. Thus, future studies should target specific patient populations, including Spanish clinical samples, in order to provide such psychometric properties.

Finally, the need for longitudinal studies that provide evidence of the predictive validity of the S-FNAME remains. The BBHI study aims to determine brain health predictors and includes S-FNAME as one possible early marker of changes associated with aging (Cattaneo et al., 2018).

\section{ACKNOWLEDGEMENTS}

A special thanks is extended to all participants and other partners (Ad-Salutem Institute, Sodexo, I.C.A. Informàtica y Comunicaciones Avanzadas, Neuroelectrics, Corporació Catalana de Mitjans Audiovisuals, Club Metropolitan, Casa Ametller, and Agència de Qualitat i Avaluació Sanitàries de Catalunya-AQuAS) for their invaluable collaboration.

\section{FINANCIAL SUPPORT}

The research leading to these results has received funding from "la Caixa" Foundation (grant agreement $\mathrm{n}^{\circ}$ LCF/PR/PR16/ 11110004) and also from Institut Guttmann and Fundació Abertis. David Bartrés-Faz was funded by the Spanish Ministry of Economy and Competitiveness (MINECO; PSI2015-64227-R) and a Institut Català de Recerca i Estudis Avançats ICREA Acadèmia 2019 award. Josep M. Tormos was partly supported by INNOBRAIN (COMRDI15-1-0017). Ad-Salutem Institute, Sodexo SA, ICA Informática y Comunicaciones Avanzadas, Neuroelectrics, Corporació Catalana de Mitjans Audiovisuals, Club Metropolitan, Casa Ametller, and Agència de Qualitat i Avaluació Sanitàries de Catalunya-AQuAS are commercial companies supporting the Barcelona Brain Health Initiative and this study. The funders had no role in study design, data collection, analysis, decision to publish, or manuscript preparation.

\section{CONFLICT OF INTEREST}

The authors have nothing to disclose. 


\section{ETHICAL STATEMENT}

The present research was conducted and completed in accordance with the principles of the Helsinki Declaration. Before being included in the study all participants provided explicit informed consent and the protocol was approved by the Comité d'Ėtica i Investigació Clínica de la Unió Catalana d'Hospitals, local ethics committee.

\section{REFERENCES}

Alegret, M., Espinosa, A., Vinyes-Junqué, G., Valero, S., Hernández, I., Tárraga, L.B., ... Boada, M. (2012). Normative data of a brief neuropsychological battery for Spanish individuals older than 49. Journal of Clinical and Experimental Neuropsychology, 34(2), 209-219. doi: 10.1080/13803395. 2011.630652

Alegret, M., Muñoz, N., Roberto, N., Rentz, D., Valero, S., Gil, S., ... Boada, M. (2020). A computerized version of the Short Form of the Face-Name Associative Memory Exam (FACEmemory®) for the early detection of Alzheimer's disease. Alzheimer's Research \& Therapy, 12(25), 1-11. doi: 10.1186/s13195-02000594-6

Alegret, M., Rodriguez-Gomez, O., Espinosa, A., Ortega, G., Sanabria, A., Valero, S., ... Boada, M. (2015). Concordance between subjective and objective memory impairment in volunteer subjects. Journal of Alzheimer's disease, 48, 1109-1117. doi: 10.3233/JAD-150594

Alegret, M., Valero, S., Ortega, G., Espinosa, A., Sanabria, A., Hernández, I., ... Boada, M. (2015). Validation of the Spanish version of the face name associative memory exam (S-FNAME) in cognitively normal older individuals. Archives of Clinical Neuropsychology, 30(7), 712-720. doi: 10.1093/arclin/acv050

Amariglio, R., Frishe, K., Olson, L., Wadsworth, L., Lorius, N., Sperling, R.A., \& Rentz, D. (2012). Validation of the Face Name Associative Memory Exam in cognitively normal older individuals. Journal of Clinical and Experimental Neuropsychology, 34(6), 580-587. doi: 10.1080/13803395. 2012.666230

Andreano, J.M. \& Cahill, L. (2009). Sex influences on the neurobiology of learning and memory. Learning \& Memory, 16, 248-266.

Blesa, R., Pujol, M., Aguilar, M., Santacruz, P., Bertran-Serra, I., Hernández, G., ... NORMACODEM Group (2001). Clinical validity of the 'mini-mental state' for Spanish speaking communities. Neuropsychologia, 39(11), 1150-1157. doi: 10.1016/ s0028-3932(01)00055-0

Buckley, R. \& Pascual-Leone, A. (2020), Age-related cognitive decline is indicative of neuropathology. Annals of Neurology, 87(6), 813-815. doi: 10.1002/ana.25733

Cattaneo, G., Bartrés-Faz, D., Morris, T.P., Sánchez, J.S., Macià, D., Tarrero, C., ... Pascual-Leone, A. (2018). The Barcelona brain health initiative: A cohort study to define and promote determinants of brain health. Frontiers in Aging Neuroscience, 10, 321. doi: 10.3389/fnagi.2018.00321

Costello, A.B. \& Osborne, J.W. (2005). Best practices in exploratory factor analysis: Four recommendations for getting the most from your analysis. Practical Assessment, Research and Evaluation, 10(7), 1-9.

Del Pino, R., Peña, J., Schretlen, D., Ibarretxe-Bilbao, N., \& Ojeda, N. (2015). Multisite study for norming and standardizing neuropsychological instruments in healthy people for Spanish population: Methods and characteristics of Normacog project. Revista de Neurología, 61(2), 57-65.

Duke-Han, S., Nguyen, C.P., Stricker, N.H., \& Nation, D.A. (2017). Detectable neuropsychological differences in early preclinical Alzheimer's disease: A meta-analysis. Neuropsychology Review, 27(4), 305-325. doi: 10.1007/s11065-017-9345-5

Estévez-González, A., Kulisevsky, J., Boltes, A., Otermín, P., \& García-Sánchez, C. (2003). Rey verbal learning test is a useful tool for differential diagnosis in the preclinical phase of Alzheimer's disease: Comparison with mild cognitive impairment and normal aging. International Journal of Geriatric Psychiatry, 18, 1021-1028. doi: 10.1002/gps.1010

Evers, A., Sijtsma, K., Lucassen, W., \& Meijer, R. (2010). The Dutch review process for evaluating the quality of psychological tests: History, procedure, and results. International Journal of Testing, 10, 295-317. doi: 10.1080/15305058.2010.518325.

Ferreira, A. \& Campagna, I. (2014). The rey auditory verbal learning test: Normative data developed for the Venezuelan population. Archives of Clinical Neuropsychology, 29, 206-215

Folstein, M. F., Folstein, S.E., \& McHugh, P.R. (1975). "Mini-mental state". A practical method for grading the cognitive state of patients for the clinician. Journal of Psychiatric Research, 12(3), 189-198. doi: 10.1016/0022-3956(75)90026-6

Hair, J., Anderson, R., Tatham, R., \& Black, W. (1999). Análisis Multivariante (5th. ed.). Madrid: Prentice Hall.

Henson, R.N., Campbell, K.L., Davis, S.W., Taylor, J.R., Emery, T., Erzinclioglu, S., ... Kievit, R.A. (2016). Multiple determinants of lifespan memory differences. Scientific Reports, 6, 32527. doi: 10.1038/srep32527

Instituto Nacional de Estadística [INE] (2019). Anuario Estadístico De España 2019. Madrid: INE. https://www.ine.es/prodyser/ pubweb/anuario19/anu19_completo.pdf

Josefsson, M., De Luna, X., Pudas, S., Nilsson, L.G., \& Nyberg, L. (2012). Genetic and lifestyle predictors of 15-year longitudinal change in episodic memory. Journal of the American Geriatrics Society, 60(12), 2308-2312.

Jurick, S.M., Weissberger, G.H., Clark, L.R., Wierenga, C.E., Chang, Y.L., Schiehser, D.M., ... Bondi, M.W. (2018). Faulty adaptation to repeated face-name associative pairs in mild cognitive impairment is predictive of cognitive decline. Archives of clinical neuropsychology: the official journal of the National Academy of Neuropsychologists, 33(2), 168-183. doi: 10.1093/ arclin/acx056

Kielb, S., Weintraub, S., Rogalski, E., Weitner, B., \& Rademaker, A. (2015). Subjective cognitive complaints are associated with longitudinal changes in episodic memory. Alzheimer's \& Dementia, 11 (7), 342-357. doi: 10.1016/j.jalz.2015.06.211

Kormas, C., Megalokonomou, A., Zalonis, I., Evdokimidis, I., Kapaki, E., \& Potagas C.(2018): Development of the Greek version of the Face Name Associative Memory Exam (GR-FNAME12) in cognitively normal elderly individuals. The Clinical Neuropsychologist, 32(1), 152-163. doi: 10.1080/ 13854046.2018.1495270

Lavoie, M., Bherer, L., Joubert, S., Gagnon, J., Blanchet, S., Rouleau, I., ... Hudon, C. (2018). Normative data for the Rey Auditory Verbal Learning Test in the older French-Quebec population. The Clinical Neuropsychologist, 32(1), 1-14. 10.1080/ 13854046.2018.1429670

Lezak, M., Howieson, D., \& Loring, D. (2004). Neuropsychological Assessment (4th ed.). New York: Oxford University Press.

Lim, Y.Y., Kalinowski, P., Pietrzak, R.H., Laws, S.M., Burnham, S.C., Ames, D., ... Maruff, P.T. (2018). Association of $\beta$-amyloid and 
apolipoprotein E $\epsilon 4$ with memory decline in preclinical Alzheimer disease. JAMA Neurology, 75(4), 488-494. doi: 10.1001/ jamaneurol.2017.4325

Loewenstein, D. A., Curiel, R. E., Duara, R., \& Buschke, H. (2018). Novel cognitive paradigms for the detection of memory impairment in preclinical Alzheimer's disease. Assessment, 25(3), 348-359. doi: 10.1177/1073191117691608

Mulaik, S. (2009). Linear Causal Modeling with Structural Equations. Boca Ratón: CRC Press.

Nilsson, J. \& Lövdén, M. (2018). Naming is not explaining: Future directions for the "cognitive reserve" and "brain maintenance" theories Rik Ossenkoppele. Alzheimer's Research and Therapy, 10(1), 1-7. doi: 10.1186/s13195-018-0365-z

Papp, K., Amariglio, R., Dekhtyar, M., Roy, K., Wigman, S., Bamfo, R., ... Rentz, D. (2014). Development of a psychometrically equivalent short form of the face-name associative memory exam for use along the early Alzheimer's disease trajectory. The Clinical Neuropsychologist, 28(5), 771-785. doi: 10. 1080/13854046.2014.911351

Pause, B.M., Zlomuzica, A., Kinugawa, K., Mariani, J., Pietrowsky, R., \& Dere, E. (2013). Perspectives on episodic-like and episodic memory. Frontiers in behavioral neuroscience, 7, 33. doi: 10. 3389/fnbeh.2013.00033

Peña-Casanova, J., Casals-Coll, M., Quintana, M., SánchezBenavides, G., Rognoni, T., Calvo, L., ... Manero, R. (2012). Spanish normative studies in a young adult population (NEURONORMA young adults Project): Methods and characteristics of the sample. Neurología, 27(5), 253-260. doi: 10.1016/j. nrleng.2011.12.008.

Peña-Casanova, J., Quiñones-Ubeda, S., Gramunt-Fombuena, N., Quintana, M., Aguilar, M., Molinuevo, J.L., ... NEURONORMA Study Team. (2009). Spanish Multicenter Normative Studies (NEURONORMA Project): norms for the Stroop color-word interference test and the Tower of LondonDrexel. Archives of clinical neuropsychology: the official journal of the National Academy of Neuropsychologists, 24(4), 413-429. doi: 10.1093/arclin/acp043.

Polcher, A., Frommann, I., Koppara, A., Wolfsgruber, S., Jessen, F, \& Wagner, M. (2017). Subjective cognitive complaints and objective cognitive function in aging: A systematic review and metaanalysis of recent cross-sectional findings. Journal of Alzheimer Disease, 56(3), 1185-1196. doi: 10.3233/JAD-160637

Prieto, G. \& Muñiz, J. (2000). Un modelo para evaluar la calidad de los test utilizados en España. Papeles Del Psicólogo, 77, 65-75.

Rentz, D., Amariglio, R., Becker, J., Frey, M., Olson, L., Frishe, K., ... Sperling, R. (2011). Face-name associative memory performance is related to amyloid burden in normal elderly. Neuropsychologia, 49(9), 2776-2783. doi: 10.1016/j. neuropsychologia.2011.06.006

Rentz, D., Rodriguez, M., Amariglio, R., Stern, Y., Sperling, R., \& Ferris, S. (2013). Promising developments in neuropsychological approaches for the detection of preclinical Alzheimer's disease: A selective review. Alzheimer's Research \& Therapy, 5(6), 58-67. doi: 10.1186/alzrt222

Rentz, D., Weiss, B., Jacobs, E., Cherkerzian, S., Klibanski, A., Remington, A., ... Goldstein, J. (2017). Sex differences in episodic memory in early midlife: Impact of reproductive aging.
Menopause, 24(4), 400-408. doi: 10.1097/GME 0000000000000771.

Ritchie, K., Ropacki, M., Albala, B., Harrison, J., Kaye, J., Kramer, J., ... Ritchie, C. (2017). Recommended cognitive outcomes in preclinical Alzheimer's disease: Consensus statement from the European Prevention of Alzheimer's Dementia project. Alzheimer's \& Dementia, 13(2), 186-195. doi: 10.1016/j.jalz. 2016.07.154.

Rodriguez-Gomez, O., Sanabria, A., Perez-Cordon, A., SanchezRuiz, D., Abdelnour, C., Valero, S., ... Boada, M. (2017). FACEHBI: A prospective study of risk factors, biomarkers and cognition in a cohort of individuals with subjective cognitive decline. Study rationale and research protocols. The Journal of Prevention of Alzheimer's Disease, 4(2), 100-108. https://doi. org/10.14283/jpad.2016.122

Rubiño, J.A. \& Andres, P. (2018). The face-name associative memory test as a tool for early diagnosis of Alzheimer's disease. Frontiers in Psychology, 9, 1464. doi: 10.3389/fpsyg.2018.01464.

Sanabria, A., Alegret, M., Rodriguez-Gomez, O., Valero, S., Sotolongo-Grau, O., Monté-Rubio, G., ... Gailhajanet, A. (2018). The Spanish version of Face-Name Associative Memory Exam (S-FNAME) performance is related to amyloid burden in Subjective Cognitive Decline. Scientific Reports, 8(1), 3828-3826. doi: 10.1038/s41598-018-21644-y

Schmidt, M. (1996). Rey Auditory and Verbal Learning Test: A handbook. Los Ángeles: Western Psychological Services.

Silva, D., Guerreiro, M., Santana, I., Rodrigues, A., Cardoso, S., Maroco J., \& de Mendoça, A. (2013). Prediction of long-term (5 years) conversion to dementia using neuropsychological tests in a memory clinic setting. Journal of Alzheimer's Disease, 34(3), 681-690. doi: 10.3233/JAD-122098.

Speer, P., Minnerup, H., Bruchmann, S., Bracht, D., Stehling, C., Thielsch, M., ... Lohmann, H. (2013). Age- and gender-adjusted normative data for the German version of Rey's Auditory Verbal Learning Test from healthy subjects aged between 50 and 70 years. Journal of Clinical and Experimental Neuropsychology, 36(1), 32-42. doi: 10.1080/13803395.2013.863834.

Then, F.S., Luck, T., Angermeyer, M.C., \& Riedel-Heller, S.G. (2016). Education as protector against dementia, but what exactly do we mean by education?. Age and Ageing, 45(4), 523-528. doi: 10.1093/ageing/afw049

Tromp, D., Dufour, A., Lithfous, S., Pebayle, T., \& Després, O. (2015). Episodic memory in normal aging and Alzheimer disease: Insights from imaging and behavioral studies. Ageing Research Reviews, 24, 232-262. doi: 10.1016/j.arr.2015.08.006

Vila-Castelar, C., Papp, K., Amariglio, R., Torres, V., Baena, A., Gomez, D., ... Quiroz, Y. (2019). Validation of the Latin American Spanish version of the facename associative memory exam in a Colombian Sample. The Clinical Neuropsychologist, 34(1), 1-12. doi: 10.1080/13854046.2019.1690050

Wechsler, D. (2012). WAIS-IV. Escala de inteligencia de Wechsler para adultos-IV. Manual De Aplicación Y Corrección. Madrid: NCS Pearson, Inc.

Weintraub, S., Dikmen, S., Heaton, R., Tulsky, D., Zelazo, P., Bauer, P., ... Gershon, R. (2013). Cognition assessment using the NIH Toolbox. Neurology, 80(11), 54-64. doi: 10.1212/ WNL.0b013e3182872ded 